\title{
As disputas argumentativas em torno do novo Código Florestal no Twitter: comunicação, eco- nomia e sociedade na perspectiva ambiental
}

The argumentative disputes concerning the new Forestry Code on the Twitter: communication, economics and society under the environmental perspective

Las disputas argumentativas alrededor del Nuevo Código Forestal en Twitter: comunicación, economía y sociedad en la perspectiva ambiental

\section{Priscila Muniz de Medeiros}

- Doutoranda e mestre em Comunicação pela Universidade Federal de Pernambuco (UFPE)

- Graduada em Jornalismo pela UFPE

- Pesquisa as interfaces entre comunicação, meio ambiente e cidadania

- E-mail: prismuniz@gmail.com

\section{José Afonso da Silva Júnior}

- Pós-doutor pela Universidade Pompeu Fabra, de Barcelona, Espanha

- Doutor e mestre em Comunicação e Cultura Contemporânea pela Universidade Federal da Bahia (UFBA)

- Graduado em Jornalismo pela Universidade Federal de Pernambuco (UFPE)

- Professor adjunto da UFPE

- E-mail: zeafonsojr@gmail.com 


\title{
Resumo
}

O presente artigo teve como objetivo analisar quanti e qualitativamente os fluxos comunicativos no Twitter sobre as mudanças no Código Florestal, visando entender se o ambiente comunicativo desse microblog foi ou não usado de modo a manifestar uma pluralidade de discursos e argumentos envolvendo diferentes posições na disputa. Depois de comprovar parcialmente tal pluralidade, os argumentos utilizados pelos dois lados da disputa (os favoráveis e os contrários às mudanças) foram elencados e confrontados com um referencial teórico sobre meio ambiente ancorado em questões de comunicação, economia e ciências sociais.

PALAVRAS-CHAVE: CÓDIGO FLORESTAL • MEIO AMBIENTE • NOVAS MÍDIAS • TWITTER • COMUNICAÇÃO

\begin{abstract}
This article aims at analyzing quantitatively and qualitatively the communicative flows on the Twitter concerning the changes in the Brazilian Forestry Code, in order to understand if the microblog's communicative environment was used in a way by which it could reveal a plurality of discourses and arguments involving different positions in the dispute. After this plurality was partially proven, the arguments used by both sides of the dispute (for and against the changes) were listed and confronted with a theoretical context concerning the environment anchored on communication, economics and social sciences issues.
\end{abstract}

KEYWORDS:FORESTRYCODE•ENVIRONMENT•NEWMEDIA•TWITTER•COMMUNICATION

\section{Resumen}

Este artículo tiene como objetivo analizar cuantitativa y cuantitativamente los flujos comunicativos en el Twitter sobre los cambios en el Código Forestal brasilero a fin de comprender si el ambiente comunicativo de ese microblog fue o no utilizado para manifestar una pluralidad de discursos y argumentos envolviendo diferentes posiciones en la disputa. Después de comprobar parcialmente esa pluralidad, los argumentos utilizados por ambas partes de la disputa (aquellos en favor y en contra del cambio) fueron listados y confrontados con un marco teórico sobre medio ambiente basado en cuestiones de comunicación, economía y ciencias sociales.

PALABRAS-CLAVES: CÓDIGO FLORESTAL • MEDIO AMBIENTE • NUEVAS MIDIAS • TWITTER • COMUNICACIÓN 

Código Florestal Brasileiro foi criado em 1965 para demarcar áreas de preservação da vegetação dentro das propriedades privadas, partindo do pressuposto de que as florestas e demais formas de vegetação presentes no território nacional são bens de interesse comum a todos os habitantes do País. Após muitas emendas ao texto original, um grupo de interesses formado basicamente por produtores rurais colocou na agenda política brasileira, a partir da década de 1990, a proposta de uma reformulação na legislação. Tal proposta começou a ser votada pelo Congresso Nacional no ano 2011. Dentre as mudanças propostas pelo projeto inicial apresentado na Câmara dos Deputados por Aldo Rebelo, se destacam: a modificação na medição das Áreas de Proteção Permanente (APPs) e a diminuição da obrigatoriedade da recomposição da mata ciliar dos rios de até dez metros de largura (de trinta para quinze metros de recomposição); a permissão da manutenção de atividades consolidadas nas APPs antes de 22 de julho de 2008, que na lei anterior tinham que ser recompostas; a generalização da possibilidade de inclusão das APPs na contabilidade da área de Reserva Legal, que na lei anterior eram considerados elementos independentes; o tratamento diferenciado para propriedades com até quatro módulos fiscais, entre outras ${ }^{1}$.

As questões relativas à proteção ambiental envolvem vozes diversas e atravessam diferentes tipos de interesses que se contrapõem na esfera pública verde (Cox, 2010). Nesse sentido, a comunicação é essencial para que sejam colocados em debate os vários discursos, uma vez que "poder é mais do que comunicação, e comunicação é mais do que poder. Mas o poder se fia no controle da comunicação, assim como o contrapoder depende da ruptura de tal controle" (Castells, 2009, p. 3). Uma das vozes que permeiam a esfera pública verde é a da mídia e do jornalismo ambiental, que, além de atuar como voz no debate público, por meio de suas coberturas de eventos, funciona como condutor das demais vozes que buscam exercer influência sobre a esfera pública (Cox, 2010). Dessa forma, a mídia tem uma forte influência sobre os temas ambientais que terão mais visibilidade e as formas como serão apresentados tais temas. Se, por um lado, a mídia teve êxito em dar visibilidade às questões ambientais, por outro, a cobertura que ela dá a tais temas segue os preceitos dos interesses de seu negócio (Castells, 2009), o que favorece uma cobertura fragmentada e cheia de lacunas. Assim, fica evidente que não há (nem poderia haver) neutralidade na mediação midiática entre as diversas vozes que concorrem na esfera pública verde.

O aparecimento da comunicação mediada por computadores fez surgir, no campo da comunicação, debates sobre a possibilidade de uma reanimação da esfera pública baseada numa pluralidade de vozes e discursos potencializada pelos novos meios. Foram as características próprias do ciberespaço que fizeram com que ele passasse a ser pensado como um ambiente comunicacional potencialmente mais democrático do que as mídias de massa e onde a comunicação pode ocorrer sem uma mediação institucional. Sites independentes e blogs, por exemplo, permitem que qualquer indivíduo ou organização com um pouco conhecimento digital

\footnotetext{
1 Ver: http://www2.camara.gov.br/agencia/noticias/MEIO-AMBIENTE/197556-INFOGRAFICO:-VEJA-AS-MUDANCAS-NOCODIGO-FLORESTAL-APROVADAS-NA-CAMARA.html
} 
possa expor publicamente suas ideias, ao passo que as mídias sociais, além de aparecerem como espaços de conversação, conseguem por vezes dar visibilidade a fluxos comunicacionais advindos de pessoas ou grupos sem recursos financeiros significativos. A liberação do polo de emissão (Lemos, 2009) e a velocidade de propagação de ideias, aliadas ao caráter colaborativo dos novos meios, permitem a emergência de novos fluxos comunicativos. É devido a tal potencial de pluralidade que se escolheu analisar os fluxos comunicativos a partir do Twitter, microblog ${ }^{2}$ com arquitetura aberta de informação (Zago, 2008), o que permite o acesso do pesquisador aos conteúdos publicados. Parte-se da hipótese de que ambientes comunicativos como o Twitter estão dando conta da manifestação de uma maior pluralidade de discursos acerca da questão ambiental, que teriam espaço para a propagação de opiniões e argumentos de diferentes grupos de interesse.

\section{PROCEDIMENTOS METODOLÓGICOS}

Para testar a hipótese proposta, foi feita uma análise quantitativa e qualitativa a partir do corpus da pesquisa "O papel das novas mídias no debate ambiental: uma análise dos fluxos comunicativos no Twitter sobre as mudanças no Código Florestal Brasileiro". A demarcação de posições contrárias e favoráveis às mudanças na legislação ambiental é uma das categorias analíticas da pesquisa em questão, tendo ela sido o foco deste artigo.

A amostra representativa da pesquisa consistiu nos posts ${ }^{3}$ publicados no Twitter, durante uma semana artificial, que continham os termos "código florestal". A coleta dos dados por meio de uma semana artificial foi a estratégia escolhida por permitir a obtenção de uma amostra estritamente aleatória.

A semana composta foi formada a partir de datas sorteadas no período de sete semanas entre 11 de setembro e 29 de outubro de 2011. Dessa forma, foi sorteado um dia para cada semana, de modo que só pudesse haver um domingo, uma segunda-feira e assim por diante. A composição ficou da seguinte maneira: domingo, 9 de outubro; $2^{a}$ feira, 24 de outubro; $3^{\mathrm{a}}$ feira, 27 de setembro; $4^{\mathrm{a}}$ feira, 5 de outubro; $5^{\mathrm{a}}$ feira, 20 de outubro; $6^{\mathrm{a}}$ feira, 23 de setembro; e sábado, 17 de setembro. Para cada uma das datas sorteadas, os tweets foram coletados com auxílio do software The Archivist, que armazena, acessando o mecanismo de busca do próprio Twitter, os posts que contêm as palavras-chave escolhidas, possibilitando que as informações sejam exportadas para uma planilha do Microsoft Excel.

É importante ressaltar que os meses que forneceram os dias de composição da semana artificial, setembro e outubro de 2011, se situam no período em que a mudança no Código Florestal já havia sido aprovada na Câmara dos Deputados, ato ocorrido em maio de 2011. E já estava em tramitação no Senado, que aprovou um outro texto, também modificando a legislação florestal,

\footnotetext{
2 Tipo de mídia social com limitação no tamanho das atualizações dos usuários. No caso do Twitter, o limite é de 140 caracteres.

${ }^{3}$ Um post é um conteúdo publicado em blogs ou microblogs.
} 
em dezembro do mesmo ano. Depois disso, o novo Código Florestal voltou para a Câmara, onde um texto distinto do texto do Senado foi aprovado em abril de 2012 e, finalmente, seguiu para o veto parcial da presidente Dilma Rousseff.

Ao todo, foi coletado um total de 3.963 tweets ao longo dos sete dias pesquisados ${ }^{4}$. Após a eliminação de alguns tweets para a correção de possíveis distorções ${ }^{5}$, restaram 3.457 a serem considerados na análise de conteúdo.

Para o presente artigo foram considerados os resultados da pesquisa que dizem respeito ao teor dos textos postados dentro do limite dos 140 caracteres, o que significa que não foram levados em conta os conteúdos das páginas para as quais os links presentes em alguns dos tweets direcionavam. Os tweets foram classificados de acordo com a divisão a seguir, considerando-se a categoria "teor do conteúdo":

1. Contra o novo Código Florestal;

2. A favor do novo Código Florestal;

3. Não emite opinião diretamente no tweet, mas possui link;

4. Cita o código florestal sem emitir opinião ou remeter a link;

5. Conteúdo dúbio, não identificado ou opiniões não conclusivas.

Uma vez que o foco deste artigo são as manifestações favoráveis e contrárias ao novo Código Florestal, serão apresentados aqui apenas os campos 1 e 2 da categoria "teor do conteúdo". Só foram classificados os posts que puderam ser avaliados, com algum grau de segurança, como manifestações contrárias ou favoráveis às mudanças na legislação florestal. É importante deixar claro que, nessa análise, só se consideraram esses dois eixos, o que significa que todos os que manifestaram querer mudanças na legislação foram enquadrados no campo 2, independentemente de quais mudanças foram ou não apoiadas ou sugeridas. Essa escolha foi feita porque, durante a análise, essa polarização entre sim e não foi claramente percebida nos textos dos tweets, muito provavelmente por influência da limitação dos 140 caracteres, que impossibilitam uma avaliação das propostas ponto a ponto.

Para a classificação dentro desses dois primeiros campos, foram adotados alguns critérios: 1) o uso de expressões como "concordo" "discordo", "sou a favor" "sou contra" etc.; 2) pedidos claros para que o Código Florestal seja modificado ou mantido; 3) uso de adjetivos valorativos para avaliar uma posição ou outra (projeto "sensato", "ridículo", "vergonhoso", "necessário" etc.);

\footnotetext{
${ }^{4}$ Para a obtenção desse total, foram contabilizados tanto os tweets com conteúdos próprios quanto os retweets (quando um usuário encaminha para seus seguidores conteúdo que outro usuário compartilhou no Twitter) em suas duas formas: quando o usuário copia o conteúdo da mensagem e escrever "RT" no começo dela ou mediante uma ferramenta disponível no Twitter com a qual basta que o usuário passe o mouse sobre sua timeline e clique em Retweet. O software The Archivist é capaz de captar os dois tipos de retweets, identificando, em ambos os casos, o perfil que retuitou.

${ }^{5}$ Foram desconsiderados tweets postados por perfis com características de perfis mal-intencionados (twitter-bots e perfis fakes).
} 
4) uso de alguns substantivos que, associados ao novo Código Florestal, sugerem juízo de valor ("avanços", "barbaridades", "retrocesso", "crime", "destruição" etc.); 5) uso de hashtags criadas por ambos os lados do debate como forma de demarcar posição (os movimentos contrários às mudanças no código criaram a hashtag \#florestafazadiferenca, enquanto os que se manifestaram a favor criaram a hashtag \#codigoflorestalja. Somente em uma situação específica o uso de tais hashtags não foi considerado como manifestação de opinião: quando elas foram claramente citadas para nomear as campanhas em conteúdos informativos, e não necessariamente para demonstrar apoio à causa em questão.

As opiniões contidas nos retweets foram entendidas como opiniões daqueles que os replicaram, uma vez que se partiu do pressuposto de que os usuários só "retuitam" conteúdos opinativos com os quais concordam. Essa tendência ficou clara no que diz respeito ao corpus deste trabalho.

Após a apresentação dos dados quantitativos, foram elencados os argumentos utilizados por ambos os lados identificados dentro do corpus já especificado. Também para a identificação de argumentos, só foram levados em conta os conteúdos textuais no limite dos 140 caracteres permitidos pelo Twitter, o que significa que conteúdos textuais e audiovisuais contidos nas páginas para as quais os links presentes nos tweets direcionavam não foram considerados para a presente análise.

\section{RESULTADOS E DISCUSSÃO}

Dos 3.457 tweets analisados, 649 (18,8\%) manifestaram uma opinião conclusiva sobre as mudanças no Código Florestal e, portanto, foram classificados nos campos 1 e 2 (figura 1). Foram 567 contrários $(16,4 \%)$ e 82 favoráveis $(2,4 \%)$. Levando em consideração apenas esses conteúdos que manifestaram opiniões conclusivas, temos que $87,2 \%$ deles foram contrários às mudanças no código florestal, enquanto 12,8\% foram favoráveis (figura 2).

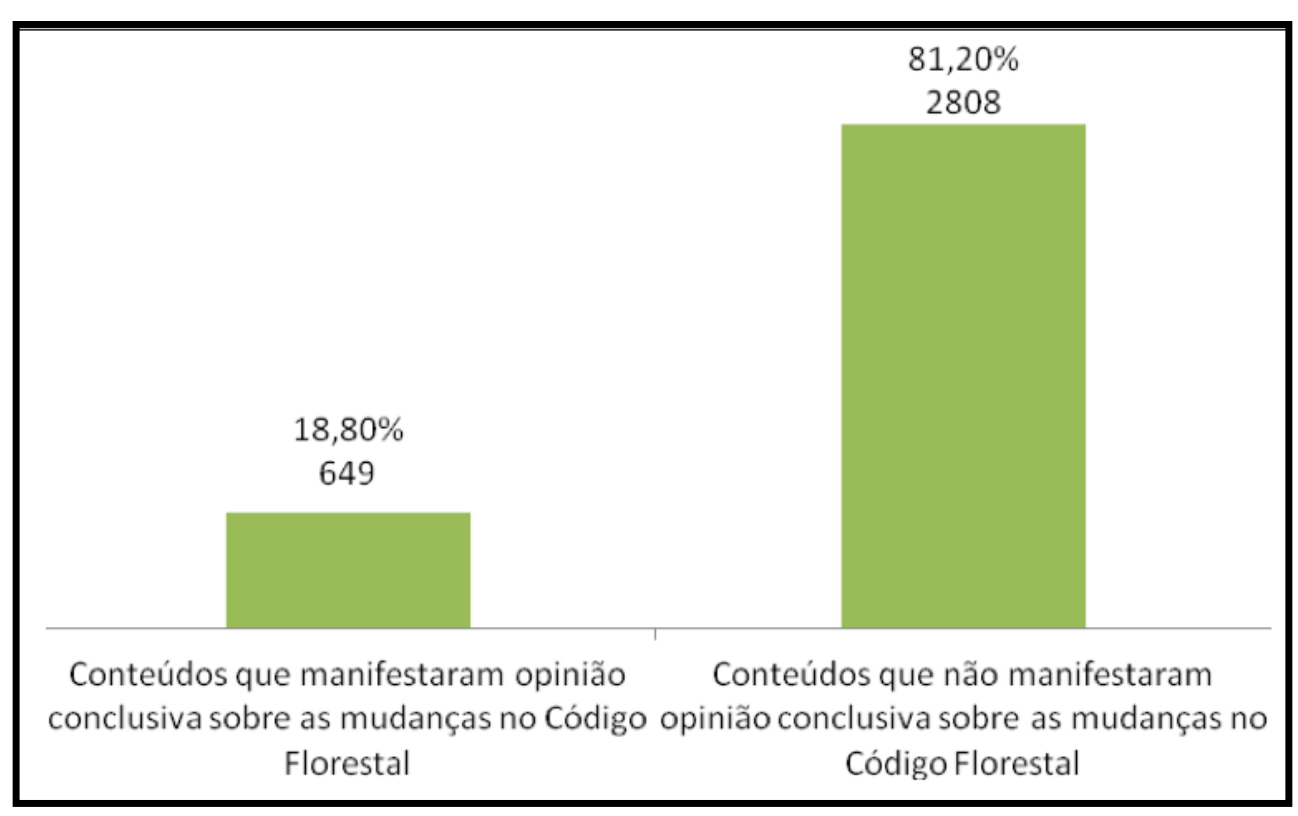

Figura 1 - Percentual de conteúdos que apresentaram e não apresentaram opinião conclusiva sobre as mudanças no Código Florestal. 


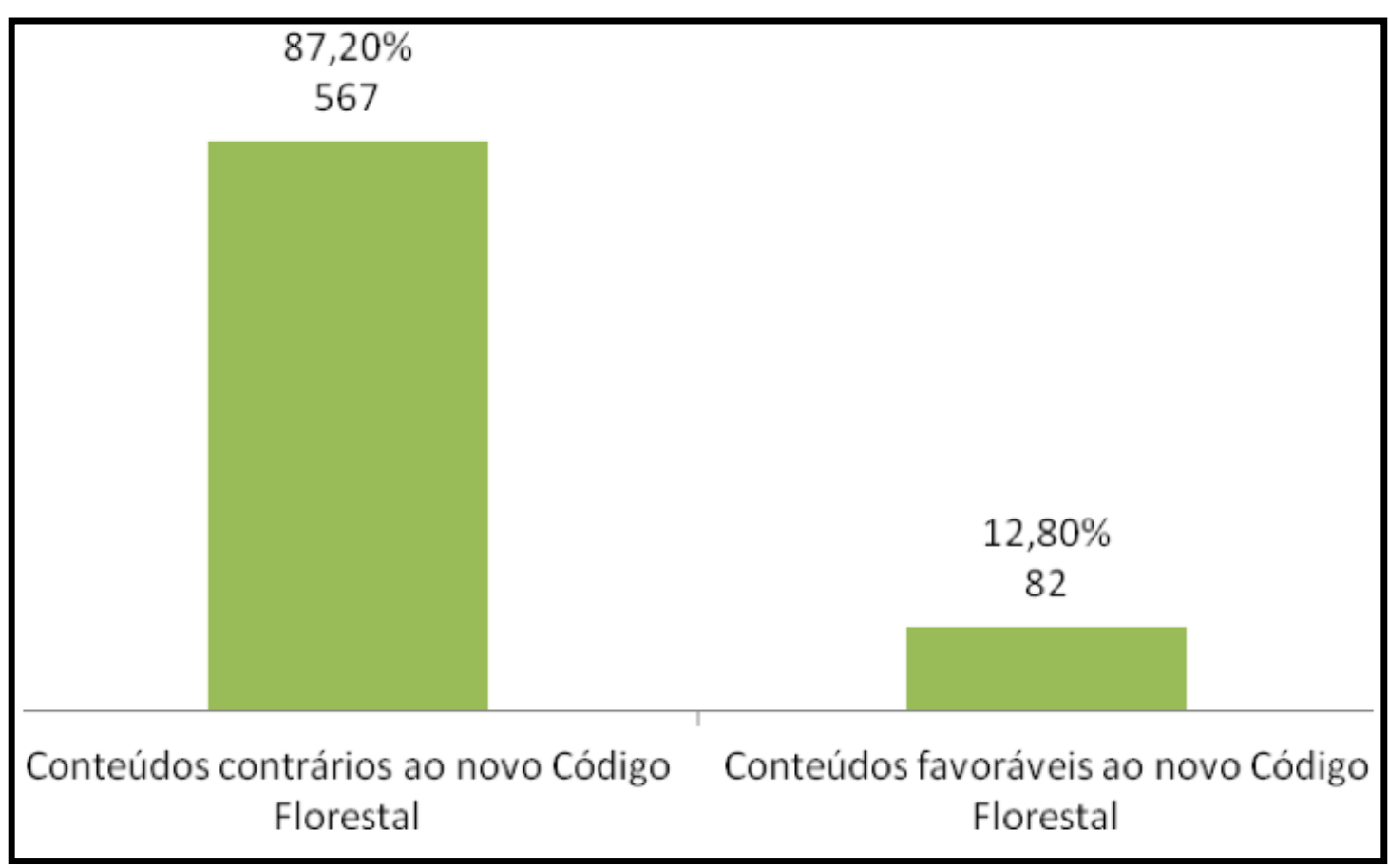

Figura 2 - Entre os tweets com opiniões conclusivas, percentagem dos contrários e favoráveis ao novo Código Florestal.

A partir dos dados apresentados, já se pode chegar a duas conclusões principais. A primeira delas é que apenas uma minoria dos conteúdos publicados no Twitter que compuseram a amostra da pesquisa continha opiniões conclusivas no interior dos 140 caracteres. Isso não indica, necessariamente, a ausência de opinião formada sobre o tema Código Florestal. Mesmo nos conteúdos configurados como conteúdos informativos é possível verificar a presença de posições. Um tweet como "Aumenta pressão social contra projeto que altera Código Florestal" (Brasil de fato - http://t.co/RG5eGdA4), apesar de formatado nos moldes do que tradicionalmente se convencionou chamar de "informação", tem notadamente a função de respaldar a posição contrária às mudanças, assim como o tweet "CNA afirma que novo Código Florestal preservará $61 \%$ dos biomas naturais" (http://t.co/LSJZXuAF) é um conteúdo informativo que pretende dar visibilidade a uma posição favorável ao novo Código Florestal. Tais casos não serão objetos deste artigo, mas são importantes para solidificar a compreensão de que a imparcialidade e a objetividade da informação são mitos, uma vez que nenhum indivíduo parte de um local de fala neutro. Também, tem que ser levado em consideração o fato de que, mesmo que no limite dos 140 caracteres de um tweet não haja uma opinião conclusiva, ela pode estar expressa nos conteúdos textuais e audiovisuais presentes nos links para os quais os mesmos apontam.

Na mesma pesquisa, foi verificado que $69.8 \%$ dos tweets pesquisados continham ligações hipertextuais para outros conteúdos externos ao Twitter, o que aponta para a complementaridade dos conteúdos presentes nos links na demarcação da posição do usuário. Com isso, a conclusão possível é de que o espaço dos 140 caracteres, provavelmente devido à sua própria limitação física, não foi usado, no caso dos debates sobre o novo Código Florestal, majoritariamente para a expressão de opiniões, mas antes como "chamadas" para outros conteúdos capazes de respaldar posições (sejam conteúdos opinativos ou informativos) e/ou localizar os leitores diante dos trâmites que envolveram o processo. 
A segunda conclusão é que a ampla maioria das pessoas que manifestaram opinião conclusiva no Twitter se posicionou de forma contrária a mudanças na legislação. $O$ apelo à opinião pública é justamente um dos argumentos usados pelos que se manifestaram contrariamente às mudanças na legislação ambiental, como será exposto mais adiante.

Entre os tweets que se manifestaram favoráveis ou contrários à mudança, nem todos continham argumentos no limite dos 140 caracteres. Muitos deles apresentavam apenas a demarcação da posição, sem, no entanto, justificar o porquê da afiliação a um lado ou outro. Foram os casos de muitos dos tweets que continhas as hashtag \#codigoflorestalja ou \#florestafazadiferenca e de outros que, apesar de adjetivarem o novo código como "sensato", "necessário", "ridículo", "cruel" etc., deixando clara a posição do usuário, não apresentavam argumentos nos 140 caracteres. Levando em conta os tweets nos quais os usuários defenderam sua posição, foram encontrados os seguintes argumentos (ao lado de cada um deles, a quantidade de vezes que foram mencionados):

\section{Argumentos contra o novo Código Florestal}

1. O novo Código Florestal diminui proteção ambiental/aumenta o desmatamento (28);

2. O novo Código Florestal é um retrocesso legal e/ou ambiental (9);

3. O novo Código Florestal promove a impunidade, anistia desmatadores (4);

4. O novo Código Florestal ameaça o futuro da humanidade (2);

5. A opinião pública é contra as mudanças no Código Florestal (2);

6. O novo Código Florestal provocará catástrofes ambientais (1);

7. A mudança visa a atender apenas os interesses financeiros dos ruralistas (1).

\section{Argumentos favoráveis ao novo Código Florestal}

1. O outro lado não tem legitimidade para falar sobre o Código Florestal (18);

2. Uma lei de 1965 precisa ser atualizada (5);

3. Necessidade de acabar coma a fome mundial (3);

4. O novo Código Florestal garante a preservação (4);

5. Necessidade de tirar agricultores da ilegalidade (2);

6. Necessidade de desenvolvimento/crescimento econômico (2);

7. O produtor rural é quem entende de meio ambiente e produção (1);

8. O novo Código Florestal trabalha com a realidade concreta (1);

9. O agronegócio gera empregos (1).

A seguir, tais argumentos serão analisados em blocos temáticos a partir de temas centrais. É interessante notar que, em vários momentos, os mesmos eixos temáticos foram usados por ambos os lados, só que em perspectivas distintas. Para os tweets mencionados na análise a seguir, foram retirados os links e os usuários para quem foram direcionados (quando havia), no intuito de facilitar a compreensão dos textos. 


\section{A proteção ambiental}

A afirmação de que o novo Código Florestal diminuiria a proteção ambiental (ponto 1 dos argumentos contrários) foi o argumento mais citado entre os contrários à alteração (28 vezes). Ele apareceu em tweets como, entre outros: "Sou contra o novo código florestal, isso vai acabar de vez com as florestas brasileiras"; "Enquanto os senadores debatem o massacre do Código Florestal Brasileiro, os índices de desmatamento voltam a subir (bit.ly/szOfwq)"; "Assine a petição pelo Código Florestal e ajude a evitar que o nosso patrimônio natural seja destruído! (\#SOSFlorestas http://t.co/6Ku4VN65)".

O argumento da proteção ambiental é a proposição mais generalista, entre as elencadas, e para a qual todos os demais argumentos parecem convergir. Tal argumento evidencia que o movimento ambiental conseguiu, seja numa perspectiva protecionista ou conservacionista, pacificar na sociedade civil o discurso de que o desmatamento é algo extremamente negativo. Pesquisas apontam que a consciência do público sobre questões ambientais vem aumentando significantemente desde o primeiro Dia da Terra, em 1970 (Castells, 2009). É por causa desse apelo da opinião pública contra o desmatamento que mesmo os defensores da flexibilização da legislação, apesar de estarem numa posição contrária à dos movimentos ambientalistas, também utilizam o discurso da proteção ambiental (ponto 4 dos argumentos favoráveis), como no caso dos tweets "O novo Código Florestal consegue reconciliar a preservação ambiental com um projeto nacional de desenvolvimento para o Brasil"; "Mas p/ o Brasil continuar c/ enorme patrimônio ambiental e ajudar a reduzir fome no mundo, código florestal precisa mudar". "Que discussão posso empobrecer? Você diz que o código florestal é 'grande perigo'? Qual? Já afirmei, ele GARANTE a preservação!". Percebe-se, portanto, que no corpus do trabalho não foram encontradas vozes dos movimentos antiambientalistas (Cox, 2010), uma vez que o que caracteriza tais vozes é o discurso explícito de que a preservação ambiental é algo não importante ou não desejável. No caso em questão, mesmo o lado favorável às mudanças no Código Florestal não trabalha com discursos que minimizam a importância da preservação ambiental, mas sim afirmam que o novo código será capaz de dar conta da preservação.

\section{A legislação}

Uma fração considerável dos argumentos de ambos os lados se fia na questão do direito, mais especificamente na legislação por si mesma. Do lado dos contrários às mudanças na lei, dois argumentos se focam nessa questão (os pontos 2 e 3 da lista apresentada), somando um total de treze tweets. Já do lado favorável às mudanças, temos mais três argumentos (os pontos 2, 5 e 8), que juntos somam oito tweets. Os argumentos podem ser divididos em duas oposições interpretativas interessantes. A primeira delas é o tratamento das mudanças de um lado como "retrocesso" e do outro como "atualização" ou "modernização". Tal oposição pode ser 
verificada nos seguintes tweets: "Já leu o antigo e o novo código florestal, para compará-los? Não acha necessário atualizar uma lei de 1965? (\#SouPCdoBsouBrasil); "O Código Florestal atual todo remendado deixa $90 \%$ dos produtores na ilegalidade por isso tem que ser modernizado". @sibamachado13 - "+1vz parabéns pelo seu posicionamento contrário ao retrocesso d novo código florestal! A Amazônia precisa de políticos assim"; e "Alterações no Código Florestal são incompatíveis com princípio da proibição de retrocessos (\#Sustentabilidade)"

A outra oposição diz respeito à relação comportamento normativo versus comportamento atual. Enquanto um lado defende que a lei seja alterada para tirar os proprietários rurais da ilegalidade, o outro defende que tal modificação significaria impunidade e que aqueles que não cumpriram a lei devem ser punidos para que passem a segui-la. Essa divergência interpretativa está presente, por exemplo, nos seguintes tweets: "Os comunistas, com o novo código florestal, tiraram 5 milhões de pequenos agricultores pobres da ilegalidade (\#SouPCdoBsouBrasil)"; "O Código Florestal atual todo remendado deixa $90 \%$ dos produtores na ilegalidade por isso tem que ser modernizado; "Não vejo nada de antimarxista no código florestal. Pelo contrário, analisa a realidade concreta e prevê medidas efetivas"; "\#Protesto: contra o novo Código Florestal, que anistia os devastadores e aumenta a devastação via @iProtesto"; e _ "Quem tem que adequar são produtores que desmatam APP, ñ tem Reserva Legal e não o Código Florestal para atender irregulares"

\section{A legitimidade}

Uma outra disputa diz respeito a que lado tem a legitimidade para impor sua posição a respeito das mudanças na legislação. Neste tópico, foram analisados os pontos 5 e 7 dos argumentos contrários e 1 e 7 dos favoráveis. Os favoráveis às mudanças no Código Florestal atacaram a campanha "Floresta faz a diferença", promovida pelos movimentos ambientalistas, argumentando que os artistas que participaram dela não têm elementos para opinarem sobre o assunto. Tal argumento apareceu nos seguintes tweets: "Artistas opinando no Código Florestal... É o mesmo que um agrônomo comentar a entrega do Oscar! - \#boigordo \#codigoflorestalja”, que foi replicado dezesseis vezes dentro do corpus da pesquisa, e "Marcos Palmeira e o dia da Marmota Jurídica, ahahaaha... outro ator falando do que não conhece - \#codigoflorestalja". Do outro lado, se defende que a legitimidade pertence à opinião pública, o que demonstram os seguintes tweets: "85\% dos brasileiros são contra as alterações no Código Florestal aprovado na Câmara. O Senado pode corrigir isso \#JovenesVerd"; e "Senhora presidenta... Faça a vontade do povo, não deixe que o novo código florestal seja aprovado!"

Manuel Castells (2009) explica que os movimentos ambientais frequentemente usam celebridades para conseguir mais atenção do público, uma vez que os artistas têm mais acesso do que outros ativistas às chamadas soft news, que são a fonte de informação principal de uma parte considerável das pessoas. "Tal deslocamento para as soft news afeta a formação da opinião 
pública" (Castells, 2009, p. 328). Se a alegada "falta de conhecimento" das celebridades é usada pelos favoráveis às mudanças no código para desqualificar o movimento ambientalista, ao mesmo tempo ela é uma arma dos ambientalistas para conquistar cada vez mais a opinião pública. E o respaldo da opinião pública aparece como o argumento de legitimidade dos contrários às mudanças no Código Florestal, ancorados no significado último da palavra democracia.

Como já foi apontado, $87,2 \%$ dos tweets que manifestaram opiniões conclusivas sobre a questão dentro do corpus da pesquisa foram contra a alteração na lei ambiental. Tal resultado coincide com uma pesquisa da Datafolha, indicando que $85 \%$ da população acredita que o Código Florestal deve priorizar a preservação das florestas e rios, mesmo que isso prejudique a produção agropecuária ${ }^{6}$. Ao analisar a história recente da legislação ambiental norte-americana, Cox (2010) defende que existe uma constante queda-de-braço entre, de um lado, a sociedade civil preocupada com questões ambientais, que quer o cumprimento ou endurecimento das leis e, do outro, o governo e grupos de interesse específicos, que constantemente buscam o afrouxamento da legislação ambiental. Já Gomes (2005, p. 221) enxerga uma blindagem antipúblico do nosso modelo de democracia representativa, "o que diminui consideravelmente a real dimensão e o real impacto da opinião pública".

Outro aspecto que gera oposições em relação à questão da legitimidade é o lugar de fala do proprietário rural. O lado favorável às mudanças defende que a legitimidade da fala está do lado dos produtores rurais no tweet "Amigos, ninguém depende mais do meio ambiente do que o próprio produtor rural. Por isso a necessidade de adequarmos um novo Código Florestal". Ao mesmo tempo, o outro lado procura desconstruir tal relação de legitimidade ao denunciar que a posição desse grupo visa a um interesse particular, o que se verifica no tweet "Do que adianta essas mulas mudarem o código florestal para ganharem mais \$? Eles ainda vão viver num mundo que sofrerá consequencias..." Tal perspectiva está ancorada num argumento básico do movimento ambientalista, resumido por Enrique Leff (2009, p. 51-52) da seguinte forma:

O processo capitalista de produção, fundado na propriedade privada dos meios de produção e na tendência para a maximização dos lucros privados no curto prazo levou a reverter os custos de produção da empresa para a sociedade, contaminando o meio ambiente e deteriorando as bases de sustentabilidade do processo econômico.

\section{A economia}

A questão econômica aparece como um argumento central no discurso dos favoráveis às mudanças no Código Florestal. Trata-se de argumentos que apelam para a necessidade do desenvolvimento/crescimento econômico, da geração de empregos e do aumento da produção agrícola

${ }^{6}$ Ver: http://www1.folha.uol.com.br/ambiente/929142-datafolha-indica-que-80-rejeitam-corte-de-protecao-a-matas.shtml 
(pontos 3, 6 e 9). Tais posições estão presentes em tweets como: "Temos fome pra matar, empregos pra criar, economia para mover... o novo Código florestal cria condições para que isto ocorra..."; "O novo Código Florestal consegue reconciliar a preservação ambiental com um projeto nacional de desenvolvimento para o Brasil”; e “@aldorebelo. Os produtores de alimento e geradores de emprego desse país estão com você. Contamos com a aprovação do novo código florestal".

Boaventura de S. Santos (1999) indica que o argumento econômico atual está baseado na premissa de que o desenvolvimento social é medido por meio do crescimento econômico, que é contínuo e ancorado na industrialização e no desenvolvimento tecnológico, também tidos como infinitos. Tal lógica trata os danos ambientais provocados por esse modelo de desenvolvimento como externalidades do processo econômico (Cavalcanti, 2010). Para o movimento ecológico, é justamente essa lógica que provocou e agrava a cada dia a crise ambiental vigente, pois "tudo que cresce acima de um certo nível sucumbe a seu próprio peso" (Moscovici, 2007, p. 38). É por isso que teóricos como Herman Daly acreditam que a saída para a decadência ecológica está numa condição estacionária de crescimento econômico, que não significaria uma situação estática, mas uma melhora na economia em termos qualitativos por meio de substituições, por exemplo, de energia fóssil por energia limpa (Veiga, 2005). Já Georgescu (apud Veiga, 2010, p, 112). acredita que "em algum momento no futuro, a humanidade deverá apoiar a continuidade do seu desenvolvimento na retração, isto é, com o decréscimo do produto. O oposto do sucedido nos últimos dez mil anos". A mudança da lógica econômica da modernidade implicaria um novo paradigma de sociedade (Capra, 2006; Leff, 2009; Morin, 2011; Santos, 1999, 2002), para a qual seria necessário "conceber uma nova maneira de produzir, de consumir e de viver" (Moscovici, 2007, p. 38).

Um dos argumentos para a importância do aumento da produção é a necessidade de se matar a fome no mundo, num cenário onde o crescimento demográfico continua acelerado. A partir de uma análise histórica da produção mundial de grãos e da situação nutritiva das populações, Santos (1999, P. 255) conclui que "a fome e a má nutrição não dependem tanto do nível de produção agrícola ou do nível geral da prosperidade do país, como das assimetrias sociais, do abismo crescente entre ricos e pobres". Tal abismo seria provocado justamente pelo modelo de desenvolvimento vigente, que, por si só, seria incapaz de resolver o problema. "Como num sistema de desigualdades o crescimento poderá produzir outra coisa que não seja desigualdade? (...) O crescimento passa, as desigualdades ficam" (Moscovici, 2007, p. 39).

\section{O futuro}

A preocupação com o futuro é algo sempre presente no discurso ambientalista, e diz respeito tanto ao futuro da humanidade quanto ao futuro do planeta. Na análise em questão, tal argumento surgiu três vezes, distribuídas entre os pontos 4 e 6 dos argumentos contrários às mudanças 
na legislação. São os tweets: "C/ aprovação aumentarão as notícias de enchente e catástrofes "naturais" "Revogar o Código Florestal, como se pretende, é um retrocesso e um ecocídio: crime que inviabilizará a vida sobre o Planeta. Isso é pouco? e "A aprovação do novo código florestal é uma ameaça ao presente e ao futuro do nosso país \#florestafazadiferenca".+

Para Santos (2002) a cultura instrumental da modernidade, com seu excesso de credibilidade nas soluções técnicas, não nos incentiva a pensar no futuro. Por sua vez, Castells (2009) ao analisar a efemeridade do presente, que provocou a emergência de um tempo atemporal, percebe também o aparecimento de uma nova cultura da natureza, caracterizada pelo que Scott Lash e John Urry (1994, apud Castells, 2009) chamaram de tempo glacial, uma noção que vê as relações entre os homens e a natureza em termos evolucionários e de longa duração, que pressupõe a visão de uma solidariedade intergeracional e dos seres humanos com as demais espécies. Na literatura socioambiental atual, o termo "bem-viver" ou sumak kawsay é cada vez mais empregado. O conceito, que surge do modo de vida indígena, "é uma alternativa civilizatória que se fundamenta na construção de relações harmoniosas e de interdependência entre os seres vivos: seres humanos entre si, seres humanos e natureza" (León, 2010). Ou seja, trata-se de uma ideia civilizatória contrária ao modelo capitalista, no qual, para um ganhar, muitos têm que perder. "É um conceito de comunidade onde ninguém pode ganhar se seu vizinho não ganha" (Santos, 2010). Tal conceito visa a um presente justo e equilibrado que, por ser sustentável, permita uma perspectiva de futuro ao localizar o ser humano numa dimensão cosmológica.

\section{CONSIDERAÇÕES FINAIS}

A pesquisa em questão concluiu que o Twitter não foi usado majoritariamente para a expressão de opiniões, uma vez que apenas $18,8 \%$ dos tweets continham opiniões conclusivas sobre as mudanças no Código Florestal (649 de 3.457). Desses, também uma minoria apresentava argumentos para sustentar a posição (foram encontrados apenas 84 argumentos). Mesmo os argumentos apresentados não problematizaram profundamente a questão, parecendo-nos óbvio que tal fato se deu, entre outras razões, devido à limitação espacial imposta pelos 140 caracteres máximos do Twitter.

Nesse sentido, acredita-se que a hipótese da pluralidade de vozes e argumentos foi parcialmente confirmada, pois se, por um lado, o microblog foi espaço de expressão de opiniões para ambos os lados e foi capaz de abarcar opiniões distintas sobre o tema (ainda que as contrárias à aprovação do novo Código Florestal tenham superado quantitativamente as favoráveis), por outro, os conteúdos de caráter opinativo e, mais especificamente, argumentativos, foram bastante minoritários se comparados ao todo do corpus em questão. Tal constatação leva a crer que, ainda que a liberação do polo emissor torne o Twitter uma potencial arena para o confronto de ideias e opiniões na esfera pública verde, a limitação espacial tende a fazer com que os conteúdos não tragam argumentos. No entanto, tal fato não invalida o papel do microblog 
com o arena argumentativa, uma vez que, como mencionado, verificou-se que $69.8 \%$ dos tweets pesquisados continham ligações hipertextuais para outros conteúdos externos ao Twitter. Portanto, o conteúdo presente nesses espaços poderá apresentar mais argumentos e mais problematizações, sendo a análise desses materiais a próxima etapa da presente pesquisa.

Também se verificou que, dentre os tweets que continham opiniões conclusivas, uma ampla maioria $(87,2 \%)$ se posicionou contrariamente às mudanças no Código Florestal, resultado que coincide, como já foi apontado, com pesquisa de opinião feita pelo Instituto de Pesquisas Datafolha.

Por fim, percebeu-se que cada lado da disputa discursiva elencou argumentos que apontam para diferentes visões de mundo, cada uma ancorada numa concepção teórica distinta. Tais visões envolvem necessariamente a questão ambiental, mas não se restringem a ela. São, principalmente, modos diferentes de pensar e modelar a sociedade e sua relação com a natureza. Enquanto um lado está mais vinculado ao atual paradigma de modernidade, com seus modelos de desenvolvimento e crescimento econômico, o outro procura um elo com a humanidade, com as gerações futuras e com a biosfera como um todo, buscando novas formas de organização social que visem a um equilíbrio social e ambiental.

\section{REFERÊNCIAS}

CAPRA, Fritjof. O ponto de mutação: a ciência, a sociedade e a cultura emergente. São Paulo: Cultrix, 2006.

CASTELLS, Manuel. Communication power. Nova York: Oxford University Press, 2009.

CAVALCANTI, Clóvis. Concepções da economia ecológica: suas relações com a economia dominante e a economia ambiental. Estudos Avançados, n. 24, 2010.

COX, Robert. Environmental communication and the public sphere. Los Angeles (CA): Sage, 2010.

GOMES, Wilson. A democracia digital e o problema da participação civil na decisão política. Revista Fronteiras - Estudos Midiáticos, Porto Alegre, v. VII, n. 3, p. 214-า222, 2005.

LEFF, Enrique. Ecologia, capital e cultura: a territorialização da racionalidade ambiental. Petrópolis (RJ): Vozes, 2009.

LEMOS, André. Nova esfera conversacional. In: MARQUES, Ângela et al. (Org.). Esfera pública, redes e jornalismo. Rio de Janeiro: Ed. E-Papers, 2009. p.9-30.

LEÓN, Irene. Resignificaciones, cambios societales y alternativas civilizatorias. In: Sumak kawsay; buen vivir y cambios civilizatorios. Quito: Fedaeps, 2010. p. 7-12.

MORIN, Edgar. Rumo ao abismo? Ensaio sobre o destino da humanidade. Rio de Janeiro: Bertrand Brasil, 2011.

MOSCOVICI, Serge. Natureza: para pensar a ecologia. Rio de Janeiro: Mauad X / Instituto Gaia, 2007. 
SANTOS, Boaventura de Sousa. La hora de I@s invisibles. In: Sumak kawsay: buen vivir y cambios civilizatorios. Quito: Fedaeps, 2010. p. 13-26.

A crítica da razão indolente: contra o desperdício da experiência. São Paulo: Cortez, 2002.

Pelas mãos de Alice: o social e o político na pós-modernidade. Porto, Portugal: Afrontamento, 1999.

VEIGA, José Eli da. Desenvolvimento sustentável: o desafio do século XIX. Rio de Janeiro: Garamond, 2010.

ZAGO, Gabriela. O Twitter como suporte para produção e difusão de conteúdos jornalísticos. In: ENCONTRO NACIONAL DE PESQUISADORES DE JORNALISMO, VI, São Bernardo do Campo (SP), 19-21 de novembro de 2008. Anais... Brasília: SBPJor, nov. 2008.

Recebido em: 27.08.2012 / Aceito em: 17.10.2012 